\title{
J
}

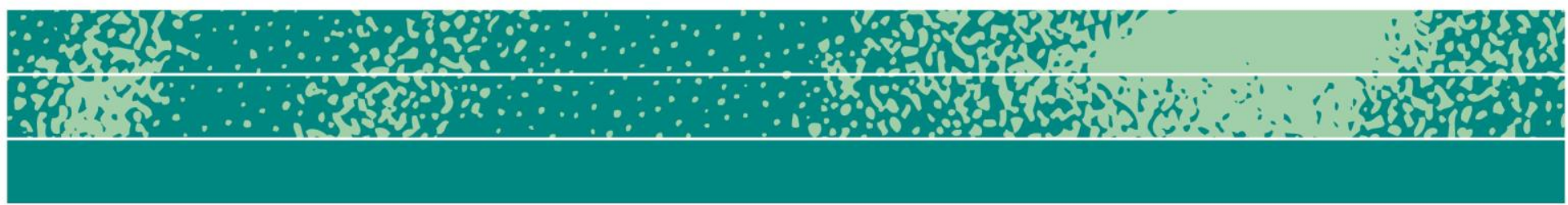

\section{Liminality, Anthropology, and the Global Organization}

\author{
Julia C. Gluesing
}

\begin{abstract}
Turner described liminality as a "realm of pure possibility" that can give rise to novel configurations of ideas within a ritual framework, while Bourdieu referred to liminality as a "space of possibles." One of the greatest challenges managers and their employees face in multinational enterprises that cross multiple boundaries is the increased complexity brought about by ambiguity, multiplicity, interdependence, and constant, rapid change. Working in global organizations means operating simultaneously in multiple contexts. Anthropologists can make a contribution to an understanding of global work by managing ambiguity and crossing boundaries; by living and working liminally-something acquired in both anthropological training and through experience; and by bringing creativity to the forefront to foster global understanding.
\end{abstract}

Page 1 of 22

\section{Keywords}

Global organization, complexity, ambiguity, change, multinationals, boundary-crossing, liminality 


\section{Introduction}

In a 2010 IBM study involving face-to-face interviews with more than 1,500 CEOs around the globe, a consistent theme emerged: the challenge posed by a rapid escalation in complexity. In a world with an unprecedented level of interconnection and interdependence, issues like global warming and climate change, access to clean water, the potential for disease to rapidly spread, and the vulnerability of our infrastructures to breakdown, keep leaders awake at night. In his introduction to the study report, then Chairman, President, and Chief Executive Officer of IBM Samuel J. Palmisano wrote (2010:4):

What we heard through the course of these in-depth discussions ... is that events, threats and opportunities aren't just coming at us faster or with less predictability; they are converging and influencing each other to create entirely unique situations. These firsts-of-their-kind developments require unprecedented degrees of creativity - which has become a more important leadership quality than attributes like management discipline, rigor or operational acumen.

Scholarly work supports this conclusion and points to the multidimensionality that arises from the many diverse socio-political, cross-cultural, and geographical boundaries that must be traversed to operate simultaneously in multiple contexts (Lane, Maznevski, and Mendenhall 2003). This complexity means that anthropologists who want to make a contribution in multinational corporations must move fluidly in an environment characterized by conditions of multiplicity, interdependence, ambiguity, and flux. Turner's concept of liminality, which was rooted in the rituals of small-scale societies, but which he also applied to modern societies, was of a "midpoint of transition... between two positions" (1974:261). Anthropologists learn about and practice the concept of liminality. They can be well suited to the work of managing complexity because they are trained to embrace liminality, either through living and working in a continual liminal state, or temporarily as part of a transition from one way of seeing or doing things to another. They routinely alternate between both emic and etic perspectives, working as both participants and observers of daily life. Yet anthropologists are best equipped for this work because their professional identity is often multiple, open to possibility, and flexibly responsive to the multidimensionality that surrounds them.

This article discusses how anthropological training provides competencies that embrace liminality and resemble those that business practitioners and international business scholars are now cataloging as essential for success in multinational corporations. In particular, emphasis is on the ability to open pathways to seeing and doing things in new ways, unleashing creative potential. The article continues with a brief 
definition and review of the concept of liminality, as it will be applied here. The discussion then turns to what it means to lead in complexity and offers some of the current managerial thinking about how best to cope with complexity. Next follows a description of the implications for anthropological training and how it can equip anthropologists to work well with complexity by helping them to accept and use ambiguity, fuzzy boundaries, and multiple perspectives to their advantage. In other words, anthropologists can learn to apply the concept of liminality in their everyday work with organizations. Finally, the article presents some of the ways anthropologists and other organizational scholars are employing the liminality concept in business. They are using this concept to develop strategies for working across boundaries, promoting learning, and opening up new possibilities for understanding and managing the rapid change, frequent transitions, and novel situations that are characteristic of today's complex global business environment.

\section{The liminality concept}

Liminality is a classical anthropological concept that focuses our attention on "inbetweenness," on the experience of being open to possibility that has the potential to uncover and to challenge deeply-rooted assumptions about how a community or a society works (Cook-Sather and Alter 2011). The concept can refer to the state of inbetweenness, or to the phase in a change process where one has given up old ways of seeing and behaving but has not yet replaced them with new ones. It is a time of possibility. When we invoke this concept and apply it to ourselves, or encourage others to apply it, we can assume a position that is "ambiguous, neither here nor there, betwixt and between all fixed points of classification" (Turner 1974:232). The position of inbetweenness is at the threshold between roles: for example, between anthropologist and business consultant, or between groups, such as an anthropology community of practice and a professional group of engineers. It thereby affords us the opportunity to gain insights into how people perceive and act in the world; into what is similar or different in people's perceptions and ways of acting; and into how to learn from these insights, creating alternatives to work in traditional, organized bureaucratic forms. In applying the concept of liminality, we open up possibilities for the new forms of organizing and ways of working described in this article, challenging our assumptions and changing our expectations. It becomes possible to build new structures better suited to our interconnected, interdependent lives that cross boundaries and contexts frequently.

Garston has suggested that liminality can help us practically embrace ambiguity and use it to explore the limits of existing structures. She uses the example of temporary employees who experience working for an organization, but not being a permanent part of the organization, to illustrate how this type of work can be a space that opens up possibilities. 
The risks and opportunities of temporary work "challenge the old boundaries of industrial organization" and suggest "new ways of organizing and experiencing work, as well as new ways of constructing organizational subjectivity" (Garston 1999:606). Yet these liminal spaces also hold the risk of undermining organizations by disrupting established routines with nothing yet to replace them and individuals' positions within the organization, leaving them in a transitional state with no established identities or roles to perform.

Turner (1995:97) described liminality as "a realm of pure possibility whence novel configurations of ideas and relations may arise"-a realm that Bourdieu (1996:236; 1991:10) discussed in terms of a "space of possibles." This idea of liminality is the focus of this article. The sections that follow provide an overview of the managerial viewpoint on complexity and what it means for leading, and working in complex global organizations, and suggests how anthropologists, through their unique training, can apply the concept of liminality to help people in their daily work as they face the challenges of complexity.

\section{Leading, managing and working in complexity}

Definitions, descriptions, and predictions about globalization and the rapid pace at which it is occurring are numerous; there are many points of view about the globalizing process and its meaning or implications for businesses and for ordinary citizens (Appadurai 1996; Friedman 2000; Stiglitz 2002). Globalization is about international economic integration and income inequality, the creation of global consumer cultures, and the crossing of many borders. The globalizing efforts of companies meet with varying successes and unintended consequences. However, in spite of the many different ways of understanding globalization, there are some emerging patterns that are important to how we think about and live in a globalized world. Lane, Maznevski, and Mendenhall (2004:8) present an accessible and comprehensive characterization of globalization by emphasizing three basic globalizing conditions that "together function as the foundation for the increasing complexity of globalization:

multiplicity, interdependence, and ambiguity." They argue that the complicated mix of global competition, the many geographies and contexts involved, with numerous cultures and languages that are all tightly linked, make things more complicated and less predictable than in the past to manage. Unpacking the three conditions of complexity is the first step to "linking complexity with the processes to manage it" (2004:9).

The first condition is multiplicity, which simply means that multinational corporations deal with many different voices, viewpoints, and constraints. People's ideas about work and how it fits in with their lives vary greatly. From the perspective of global business, multiplicity is primarily about the multiplicity of competitors, customers, suppliers 
along the value chain, multiple governments and their regulations and requirements, and the many stakeholders who monitor, or have an interest in, what businesses do and the impact they have in local communities. For example, a local grocery and variety store in the San Francisco Bay Area may find that it now has large competitors that originate not just in the U.S., but-like Tesco and IKEA-come from the UK and Sweden. McDonalds changes its food and drink offerings to suit the demands of many different customers in local markets around the world. Ford Motor Company, to create an automobile for the U.S. market, must work with and integrate the products of suppliers in Thailand, Mexico, China, Malaysia, and Brazil. Visteon Corporation, a large automotive parts supplier, in its turn, must comply not only with U.S. regulations regarding the chemical content of its manufactured products, but also with those of the EU. High tech giants like Google have found themselves embroiled in controversy when their policies about open access to information on the Internet collided with the Chinese government's policies of information control, nicknamed "The Firewall of China." Companies can also find themselves constrained by powerful non-governmental organizations like Human Rights Watch or Amnesty International, who can be powerful enough to push companies to alter their employment practices. Managing all this multiplicity is part of globalizing, but it is also a very real challenge because there are no established "how tos." Moreover, the previously successful practices of examining balance sheets and making strategic plans that are executed with discipline no longer work very well because there is so much unpredictability. Business circumstances in global markets can change over night.

The second condition of complexity caused by globalization is interdependence. All one has to do to understand this condition is to look back at the global financial collapse in 2008, or even further back to the attacks on the World Trade Center on September 11, 2001, when the stock market dove and many businesses were interrupted-especially those whose headquarters were housed in the Trade Center itself. While companies can take advantage of interdependence to drive down costs and expand into global markets, there is a downside to the extended web of relationships in which they function. A delay in shipping parts from China to the U.S. can have an enormous cost when plant production has to be shut down in the U.S. as a result. Alliances can be more complicated than imagined: take, for example, the DaimlerChrysler merger which ultimately failed, partly due to imperfect understanding of each other's operating expectations, competencies, and cultures.

Ambiguity is the third condition of complexity. No one doubts that there is an abundance of information available on the Internet and flowing through corporate infrastructures around the world. Yet the clarity of information is difficult to achieve when there are so many different meanings for the same information depending upon context and cultural perspectives; misattributions or interpretations can abound, 
especially when so much communication takes place using virtual technologies. For example, even in global finances and accounting it is difficult to know "the facts" of a situation when there are different reporting systems and norms for inputting or disclosing financial information in different locations around the world. Even global accounting firms like PricewaterhouseCoopers cannot ensure that what one country reports on a balance sheet will be equivalent to another's.

Equivocality is another aspect of ambiguity that occurs when different interpretations of the same information are possible. At Ford Motor Company, when the company was first attempting to design a global car, a global team of product managers in different countries looked at a basic blueprint for the design of a chassis and each member came away with a different interpretation of the blueprint, one focusing on cost, one on safety, one on supplier relations, and one on manufacturability with different implications for design. It is also nearly impossible when the numbers on the spreadsheet change to know what caused the change. Cause and effect relationships in global business are particularly difficult to unpack when an abundance of related factors can be involved. For example, correlating a sales team's new global strategy to an upturn in product demand in a local market is nearly impossible because that increase could be due to many local factors, including bank policies, tariffs, or even the disappearance of a competitor.

The complexity created by multiplicity, interdependence, and ambiguity is dynamic, too. Indeed, the whole global system seems to be changing at an ever-increasing rate. Environmental conditions such as climate change and the potential scarcity of water resources, energy fluctuations due to political conflicts, and jostling for power on the global stage, are just some of the factors that influence daily fluctuations, making it difficult to decide how to act. So, how are leaders and managers responding to dynamic complexity? Scholars (Sachs 2000; Lane, Maznevski, and Mendenhall 2004) and CEOs (IBM 2010) point to the importance of requisite variety (Ashby 1973) and talented people with a global mindset and the ability to think systemically as critical to organizations' structures and policies. Organizations must "complexify" themselves, introducing a variety of perspectives and skills into their workforces. The complex and ambiguous inputs coming from the environment must be matched by an equal cognitive complexity in the people who respond. In addition, the processes must be flexible enough to allow change to occur. As Weick and Van Orden have remarked: "globalization requires people to make sense of turbulence in order to create processes that keep resources moving to locations of competitive advantage" (1990:1).

The IBM report (2010) echoes the need for systems thinking, and variety by highlighting the competencies that successful global companies foster: creativity and systems thinking with enough flexibility to change 
with speed. Systems thinking means that the parts of a system can be understood best in the context of relationships with one another and with other systems, rather than in isolation (Senge 1990). In previous IBM reports, change was cited as the most difficult challenge for CEOs to overcome. Now it is the complexity of global systems, with creativity named as the most important attribute leaders and managers can have to capitalize on complexity (2010:11): "The effects of rising complexity call for CEOs and their teams to lead with bold creativity, connect with customers in imaginative ways and design their operations for speed and flexibility to position their organizations for twenty-first century success."

\section{Anthropology and learning to embrace liminality}

The concept of liminality as a process, as a transitional state, and as an ambiguous space that frees the self or a group from the imposition of traditional structures, opening up the possibility for new ways of thinking and being, is central to the lives and work of anthropologists, no matter the context of their work or with whom they are working. The very nature of the U.S. four-field anthropological education and training demands that students embrace the study of humankind from the perspectives of physical evolution, archeology, linguistics, and culture, holding all perspectives simultaneously even if they specialize in one of the fields. It is a holistic and integrative frame that involves crossing boundaries and taking on multiple perspectives from the start.

Anthropology in many ways accomplishes deep education in a discipline while also downplaying ideological structures as determinant of interpretation, allowing structures to emerge from experience and at the boundaries of societal and organizational life. For example, students are encouraged to immerse themselves in anthropological theory to establish a solid grounding in preparation for fieldwork. Yet, while in the fieldwork experience, students also are encouraged to open up to alternative meanings and interpretations of events, relationships, and objects, from the point of view of the people they are studying. Anthropology thus moves back and forth between documented disciplinary knowledge and local knowledge, between etic and the emic perspectives, between observer and participant roles. In this sense, doing anthropology is a liminal experience of oscillating perspectives.

Field notes themselves are symbolic of the liminality that is central to anthropology, representing being in the field but not of the field. The liminality in field notes comes from three sources: (1) the anthropologist's position "betwixt and between" worlds, their own and that of the people they study; (2) the ways field notes mediate between the different roles an anthropologist might take on while in the field, and his or her own personal relationship to field notes; and (3) how field notes are a form or genre of writing and how they relate to other forms of writing (Jackson 1990). For a student, field notes are a form of ritual that 
is a necessary part of the transition from student of anthropology to professional anthropologist, especially for a student who is working towards a graduate degree. Field notes are part of ritual because they are a tangible representation of the student's role as an "outsider" in the group or society s/he is studying. They also connect the student while in the field to home and to the anthropological profession, and then, on the student's return to home base, they connect back to the field and the experience of fieldwork. Boundaries in fieldwork can be fuzzy, and a student can experience ambiguity when cultural norms and meanings are not yet known and when their own are not applicable. Roles as a participant observer can also be ambiguous: for instance, when a student is asked to participate in the work of a business team he or she is observing, even if it is just copying documents. The student assumes the role of team member for a while and is no longer in the role of researcher or observer. However, the team will not fully allow the student to be one of them, or to "go native," and will put the student back into the researcher role eventually. Field notes are a record of the continual movement between the roles of anthropologist and native and mediate this experience.

As documents, field notes also represent an emotional detachment from the field and are a central part of the science of anthropology. Yet, at the same time, they are an emotionally-laden diary of the anthropological experience, as well as a record of native confidences and expressions of their life experiences. Field notes are a detached description of the situation experienced by a student anthropologist and provide data to address an intellectual problem-the reason for the fieldwork in the first place. At the same time, field notes are also a representation of the student's experience and can provoke a flood of memories and emotion in which the field notes are a reflection of self and no longer of the field. As documents, the field notes are "raw data" that can be translated into a finished piece of writing, midway between the anthropologists and the reader of a journal article, a book, or even a fictional narrative. They are also betwixt and between a private document and one that is public. Fieldwork, and the field notes that are intimately a part of it, can prepare and test a student's ability to live with ambiguity, with an identity that is unclear to the anthropologist or to the natives' identity, and with all the uncomfortable feelings that result from this state of neither here nor there and neither this nor that (Jackson 1990).

An anthropologist's training is socialization into a life of ambiguity and inbetweenness, a liminal life, that is central to the discipline of anthropology and which continues throughout an anthropologist's career. It is excellent preparation for work as a business anthropologist in a multinational enterprise, where people are working in spaces with continually shifting boundaries, multiple cultural arenas, and diverse contexts. Anthropologists can develop a level of cultural intelligence that 
means they know and can readily transcend their own cultural background to interact with and understand people from other cultural backgrounds more readily than most. Experienced professional anthropologists who accept liminality as a way of life develop a unique ability to seek out and work with difference, and the capacity to produce new knowledge from this difference, by moving back and forth between the known and unknown. In fact, they actively seek out information about difference. As Bateson (1972:459) reminded us, "information is the difference which makes a difference." Anthropological training that emphasizes a tolerance for ambiguity is an advantage if the goal is to think in new ways and open up possibilities for new ways of working-or, simply put, for being creative.

We can do even more to train anthropology students to embrace liminality in a business setting. In educational experience, liminality can serve as "a threshold between and among clearly established roles at which one can linger, from which one can depart, and to which one can return" (Cook-Sather and Alter 2011). Specifically, students can take up a liminal position between student and professional-not with the goal of immediately transitioning from the former to the latter, but rather with the goal of accessing and acting on the insights that such an indeterminate state brings. There is also the potential for the crossing and re-crossing of boundaries to transform the ongoing relationship between anthropologist and business professional. As more anthropologists turn to the private sector for employment in global organizations, work for consulting companies that serve them, or become free-lance consultants, additional training experiences while they are being socialized into the discipline through their education would prepare them to transition from anthropology student to professional business and organizational anthropologist in the private sector. We can structure opportunities for immersion in interdisciplinary project work and offer opportunities for anthropological practice in settings that simulate, or actually are, global work settings that entail multiplicity, interdependence, ambiguity, and flux: in other words, complexity. Two examples from my own teaching experience illustrate how this additional preparation might be accomplished and the learning that the opportunity affords.

\section{Interdisciplinary project work}

As an illustration of interdisciplinary project work, I am going to describe an example from an educational collaboration at Wayne State University (WSU) where I have taught and conducted research in both the Department of Anthropology and the Department of Industrial and Systems Engineering (ISE). The particular educational program is called the Engineering Management Master's Program (EMMP), which is taught on campus in ISE and also in industry, particularly at Ford Motor Company, where the program is delivered to working engineers and paid 
for by the company as part of its leadership development (Gluesing et al. 2008). The degree is a WSU degree, no matter where it is taught. There are two years of coursework that includes a mix of engineering, business, and anthropology. In the third year of the three-year program, students work in teams on year-long leadership projects. Each team, along with its corporate sponsors, chooses a project for its global, strategic importance and because the project generally involves a knotty problem that has not yet been solved within the established organizational structure. Faculty advisors and graduate students work with the industry project teams and their company sponsors throughout the year. At the end of the year, the teams present the results of their work to top-level managers, as well as a thesis to their faculty, so there is a very important "deliverable" that the teams must produce.

Graduate students specializing in business anthropology have been fortunate to be assigned to these teams. The opportunity to interact with working engineers to solve a real-world problem, with high stakes in a setting that crosses multiple boundaries within and outside the company, is excellent preparation for what they might face after they graduate. The students move outside the discipline of anthropology and learn to "see" the world through the eyes of the engineers. They learn about the demands of the corporate environment in projects that can cross multiple locations as dispersed and diverse as Japan, Brazil, Germany, the U.S. and China, and India and the Middle East. They have to learn about "car culture" and corporate culture, and about the differences among the engineering disciplines. In their turn, anthropology students apply their skill set to conduct research for the teams and to help them as "consultants," opening possibilities to the team members through their "outsider" point of view, and illuminating cultural factors that may be hindering the resolution of the problem.

The anthropologist's work is often a part of the final deliverable. It is an eye-opening experience for the anthropology students and is often quite uncomfortable as many of their assumptions are challenged, but it invariably teaches the students to examine problems from different perspectives, to suspend judgment before making interpretations and attributing meaning, and to open up to new ways of seeing and doing things. One student, who had come to work with a project team, noted at the start of her work that she was skeptical about working with a corporation and leery of corporate exploitation: of both people and the environment. She and her fellow students in anthropology had a negative opinion of business in general, and certainly of a company like Ford which "enslaves" its engineers and makes products that "pollute."

At the conclusion of her project experience, her ideas had changed. Through her participant observation in the corporate environment, she began to realize the difficulties faced by the engineers and the ambiguity inherent in their work (what she had previously 
thought was "just calculations"), and began to see the engineers as human beings faced with nearly impossible complexity in which they had to function and make decisions. She also saw that many of the engineers really had safety and environmental preservation as strongly held personal goals, and that they loved their work. They were concerned with the safety of their families and friends who would be driving these vehicles, as well as that of the general public. For this student, the project work was liminal work and a positive, though uncomfortable, part of her transition from academe to the business world. The project work also introduced the idea of crossing cultures, and all that this process entails, as something not limited to societal boundaries. The educational structures in cultural anthropology generally do not include "the other" as another occupational, functional, professional, or unit-based culture, whereas in the multinational corporation, occupational cultural groups are often just as salient as national or societal cultures.

\section{A liminal role highlighting ambiguity}

The second example is a classroom experience. One semester I taught a graduate seminar in identity and globalization for the Department of Anthropology at WSU. I collaborated with a colleague who was teaching a course on global perspectives for the Business School (Miller et al. 2008). We arranged to have our classrooms located next to each other on one of the university's satellite campuses that was equipped with state-of-the art video conferencing capability. My colleague had established a relationship with a technical university in Germany. She and a couple of the professors there had devised an eight-week simulation to teach about, and give the students on both sides of the Atlantic some experience in, global virtual teaming. My anthropology graduate students studied the business students as they worked together using email, web chat, video and audio conferences, assuming roles on negotiation teams for a merger and/or acquisition involving a fictitious German and American company. The anthropology students did participant face-to-face participant observation, just as they would have been required to do in the "real world." They had to assume all the confidentiality and the fieldwork requirements a business anthropology project would entail, including obtaining official university Institutional Review Board (IRB) approval. The business students asked the anthropology students for reports, which the students had to provide without violating any of the rules for confidentiality, yet still provide value to the business teams to maintain their credibility.

The anthropology students experienced considerable ambiguity about assuming multiple roles as students, and team members and consultants. This type of academic-practitioner, outsider-insider role is often one that is assumed by corporate anthropologists, so it was an excellent training experience for the students in straddling boundaries 
and working in a liminal space. The students were required to prepare a final report for me based on their field notes, so they also experienced the transition from their notes to a finished write-up. The relationship to their field notes and to their report contained ambiguity about what was and was not appropriate to include in the report. The process of reflection about their liminal situation made the students aware of both the pitfalls and advantages of ambiguity as a necessary part of liminality. The students felt the stress it can produce but also experienced the understanding and insights they gained about negotiation from the business students. It was a perspective on negotiating boundaries that was not part of the anthropological perspective on identity, negotiated identity or cross-cultural negotiation they were learning about in my class.

Liminality, as a classical concept in anthropology, can be incorporated in the educational setting in many ways: through knowledge imparted by the instructor; through reading and studying; and most importantly, through experience in various settings. Cook-Sather and Alter (2011:8) remind us that a theory of liminality, that can help support and analyze transitions within formal educational contexts but also in relation to education more generally, is particularly necessary in the contemporary world, when life is constituted by multiple and overlapping liminal phases, places, and states as members of a society move from one culture, context, and role to another, often repeatedly throughout a single lifetime. This conceptualization of liminality suits multicultural theories and approaches and invites us to analyze the common educational rite of passage in new terms that can create new lenses for seeing the world and encourage questioning of dominant relations of power and dominant forms of knowledge, as well as open spaces for creativity and the generation of new knowledge. For business anthropologists in training, the two examples described here offer concrete suggestions for preparing them to assume roles in global organizations where liminality abounds and where the concept can be useful in managing complexity if employed strategically.

\section{The strategic use of liminality to manage complexity}

For anthropologists who study and who work with and within business enterprises, their education and training, especially in the field, equip them to navigate and take advantage of liminality strategically. They can leverage liminality in their own work and in creating opportunities for people in organizations, both individually and collectively, to become more flexible, to learn, to change, and to build new structures and new knowledge. People can become adaptable to an environment in continual flux if they take advantage of and foster the conditions of liminality creatively. Anthropologists are uniquely equipped to make use of liminality in their own work as employees in multinational organizations 
or as external consultants. Below I describe four aspects of organizational life that are open to liminality, and which can create opportunities for anthropologists working with and within global organizations. Liminality is a useful concept to enable organizations to manage complexity strategically through: (1) interdisciplinary, cross-boundary, multicultural project teams; (2) multi-skilling and mobility that enables flexibility; (3) creating change; and (4) engaging in identity work to make the most of workforce skills.

\section{Interdisciplinary, cross-boundary, multicultural project teams}

As more multinational corporations adopt project teams as the basis for organizing work, the concept of organization as an enduring social artifact is being challenged (Weick and Van Orden 1990; Tempest and Starkey 2004). With the temporary nature of many project teams, especially those that cross multiple cultural, organizational, and geographic boundaries, the question is raised of how learning and knowledge development takes place (Tempest and Starkey 2004). Liminal episodes can become a context for learning as new ways of organizing are being developed in multinational, globally-networked corporations. New institutional spaces that are transient, as well often as virtual spaces, can provide contexts for learning. Learning occurs across organizational boundaries in network environments constructed of linked project teams. These spaces release employees from organizational structures that bind too tightly. They can promote creativity and innovation because they challenge traditional hierarchies and create liminal situations that are "conducive to transcendence and play" (Tempest and Starkey 2004:509). Global project teams provide the opportunity to disrupt taken-forgranted routines and to try out new ones without having to establish a long-term commitment to a new process.

Networks of project teams in new product development in the automotive industry, for example, are often given a "passport" to move freely across traditional organizational boundaries and hierarchies to seek new technologies and specialized expertise, and to create new processes for developing products. There is considerable ambiguity at the start of the product development process. While employees who are part of the project teams can still carry traditional titles such as Powertrain Calibration Engineer, they may often work in new ways that do not fit the standard job description that goes with this title. These same engineers could be working on new manufacturing processes, or experimenting with others on the opposite side of the world to develop new calibration techniques or develop new engine materials. In global product development, engineers often confront new engineering challenges posed by a very different environment, such as having to design for dessert temperatures, high altitudes, or very rough road conditions. The situation is fluid and malleable, enabling new ways of 
working and new knowledge creation. Inhabiting a liminal space is their way to be creative in devising solutions to problems they may never have encountered before.

Wenger (1998) states that a community of practice is a necessary condition for knowledge generation because it provides the interpretative context for making sense of the world of work and, thus, the possibilities for learning. New forms of organizing, such as temporary project teams or new product development teams, also provide groupings of individuals that can be activated as the basis for knowledge production in recurring projects. Periodically, they can be drawn together and activated by managers who serve as network brokers. Business and organizational anthropologists and design anthropologists are often members of such teams, whether as insiders or outsiders to the formal organization. The teams present anthropologists with the opportunity to make use of liminality and transition spaces to open organizational members' thinking. They may introduce new lenses, perhaps through collaboration with another discipline, or by an employee from another part of the world with another cultural perspective or practice. Anthropologists can help build both systems thinking and creativity by introducing into the conversation a holistic view of organizing, and by making visible interdependencies that may be taken for granted.by organizational members. They can work with organizational members to use liminal opportunities as a way to break free of organizational constraints and make new connections, "complexifying themselves" by taking on diverse, alternative perspectives and "rearranging resources" to learn as individuals and to contribute to organizational learning at the same time.

\section{Multi-skilling, mobility and flexibility}

For high-performing project teams that are the basis of global networked organizations, connections and cooperation are essential, especially if organizations want to develop and benefit from new knowledge for strategic renewal and innovation. Cohen and Prusak (2001) have stated that social capital connects organizational members together and encourages cooperation. Social capital is characterized by trust and shared norms that can encourage a climate of reciprocity. Yet it is a difficult challenge to establish social capital which resides within organizations that are constantly in a state of recomposition. Instead, what is occurring more often is social capital that is work-based and in which a sense of belonging build on the project as the focus of commitment.

Organizational work centering around project teams creates new forms of social capital that themselves create network connections which transcend formal organizational boundaries and operate "within and between organizations" (Knoke 1999:18). The project becomes the focus of commitment, while people's sense of belonging builds from this 
commitment. For individual workers, this commitment can mean developing social capital that lasts beyond the project and beyond their tenure in any one organization. If they maintain connections as part of a community of practice (of engineers for example), or because of personal bonds formed during project work-especially if that work revolves around solving tough problems-they can create more fluid career paths for themselves. They also can avoid the rigidity of the career tracks imposed by formal organizational human resource systems. In the ambiguous, liminal spaces created by project work, individuals can leverage the scope of learning opportunities and develop a breadth of skills and knowledge to perform in a broader range of organizational roles. Individuals now expect to work for more firms in their career, and even for several companies simultaneously, on a broad range of projects. In this sense, liminal transitions are a new reality in organizational life.

Enabling employees to become multi-skilled with a rich portfolio of experiences increases the flexibility of the organization as a whole. The organization develops the "requisite variety" of employees to innovate and to tackle unexpected or new situations that arise in an environment that is continually in flux. Having people on board who embrace job mobility also means that project teams can be assembled quickly in different locations around the world to work on a variety of products and on problem-solving projects, both short-term and long-term.

\section{Creating change}

If we embrace the concept of liminality as a part of modern organizational life, then it is possible to see opportunities for creating organizational change-not just as a result of major environmental jolt, but also as a part of normal organizational life (Horvath 2009; Howard-Grenville et al. 2011). Organizational change programs are often intentional, but change need not be formalized. It can occur in everyday practices such as meetings or workshops that are constructed symbolically as "liminal phenomena." These events can be "bracketed," but not removed from the everyday action of organizations. "When brought into being in the hands of able actors, liminality as a cultural apparatus provides great possibility and material for endogenously creating intentional cultural change" (Howard-Grenville et al. 2011:18). Liminality can be a kind of cultural tool to enable change.

The work of Howard-Grenville and her colleagues introduces a new model of organizational change in which organizational insiders, who are not necessarily part of any managerial hierarchy, can achieve change by taking action, experimenting, and working with the symbolic richness that is present in organizational life. The model is based on three central processes: (1) resourcing the everyday as liminal; (2) engaging the liminal; and (3) translating liminal experience and seeding change. The model assumes that people actively construct together the 
meaning of the symbols that surround them, including events and behaviors. The model assumes that organizational actors are actively engaged in constructing symbols that include multiple voices, and which are polymorphic, with different meanings for different people. For example, in a French-American team, symbols for food facilitated cooperative interaction across cultural boundaries. However, the French understood the symbols to reference careful preparation of food, while the Americans interpreted the symbols in reference to eating good food. The Americans and the French team members were able to joke about their different interpretations and to see them as complementary. They used the symbols to take a broad view of each other's potential contributions to project success. Team members could see how both ideas and their implementation were important to a positive project outcome. Symbols have the potential for malleability, though translation or recombination, opening up the possibility for cultural change. Spaces can be opened up that "bracket" a topic for attention, but that leave room for "what-if" scenarios and new meanings that have the potential for changing ways of working.

Applying such a model of organizational change means that any organizational member can become a change agent. At Nike headquarters in Oregon, for example, a group of colleagues and I were invited to participate in a regularly scheduled workshop. We were outsiders brought in to attend and participate in the event, with some of us making presentations. The Nike staff, all across the headquarters location, were invited-but not compelled-to attend. The interaction was informal and included Nike symbols of sustainability, collaborative work, and sports, especially of achievement and sports icons. The workshop was about sustainability. At one point the topic of water came up in one of the presentations, which led to a discussion of water use in the manufacture of T-shirts and shoes. One of the people in the workshop began talking about the meaning of water in relation to sustainability, especially in the context of sports. Ideas came up about recycling water, and the topic changed to recycling shoes, with the focus on shoes as fluid, and so on. The workshop became a liminal space where people could draw on existing cultural resources in the form of tangible objects placed on the walls and on the tables that had multiple meanings. The objects helped people create new meanings that might lead to new thinking about how to manufacture products that use less water. The meaning for sustainability was extended to not just natural resources, but to the products themselves. Our outsider group (all "cultural experts") introduced additional resources into the workshop and juxtaposed them with existing resources in the community to foster new perspectives. Participants were encouraged to tap into others in the Nike community, as well to take the ideas from the workshop further, but without the imposition of any formal organizational mechanisms. This process preserved liminality to keep possibilities open and allow people to take 
action or experiment in their everyday work.

This Nike example illustrates how opportunities for significant culture change can be initiated through ordinary conditions, and not major crises, and as part of everyday organizational life rather than separated from it. Liminality enables culture change because it temporarily suspends normal interactions and removes them from the existing cultural repertoire, giving rise to creative improvisation through the redefinition of common symbols.

\section{Engaging in identity work}

An intriguing area of work in identity is in the area of bicultural and multicultural identity (Brannen and Thomas 2010; Fitzsimmons 2013; Fitzsimmons et al. 2011). New scholarship is arising in the study of people who have bicultural or multicultural identities as a new organizational demographic. Having a bicultural identity means that a person identifies with two or more cultures and has internalized associated cultural schemas (Fitzsimmons 2013). As the world becomes more connected and interdependent, and as immigration and migration are on the rise, demographics are changing. In the U.S., thirteen percent of the population is made up of first-generation immigrants, and twenty percent of the population speaks a language other than English at home (United Nations Statistics Division 2011). Bicultural marriages are more commonplace. For example, it is no longer unusual for an employee in a multinational corporation to be born, vfor instance, to a SenegaleseGerman woman married to a German man, but who was raised in Spain and is now working in the U.S.

People who are bicultural could be considered liminal characters. They typically are not easily defined because they do not enact a persistent identity (Sturdy, Schwarz and Spicer 2006). Bicultural or multicultural individuals have access to multiple cultural knowledge systems that they have learned as a result of significant exposure to the multiple cultures shaping their identity (Hong et al. 2000). They have the potential to facilitate boundary crossing, and thus organizational creativity and innovation, by bringing diverse people with differing perspectives together. They also can help transfer knowledge in global networked organizations. Biculturals develop more complex cultural representations and are more likely to be able to deal with cognitive complexity across domains, giving them both the empathy and flexibility "to integrate ideas in potentially novel and more creative ways" (Brannen and Thomas 2010:11). It is possible that if organizations can locate bicultural individuals already in their workforce, they can engage them in searching for ways to remain competitive in an increasingly challenging and complex environment. There is a strategic role for anthropologists in helping to find and to put the bicultural or multicultural skillset to work in global work. 


\section{Conclusion}

Liminality is part of a world of contingency, where the complex array of events, people, structures, and ideas can take on multiple meanings and move in many different directions. As a key concept in anthropology, it has the potential to push forward our practice in and theorizing about global organizations.

First, as practitioners, many anthropologists work in consulting roles, whether they are fully employed by an organization or contracted, and whether they are working inside or outside the organization, or both. Consulting itself can be seen as a liminal activity. Czarniawska and Mazza (2003) used the concept of liminality to examine the positions of both clients and consultants, concluding that they both occupy a liminal space, neither wholly inside nor outside the client organization or the consulting firm. There are often tensions about objectives and there is uncertainty about identity, position and routines. Anthropologists are good at working with this type of liminal process. Consulting anthropologists have the opportunity to create rituals in their work that will turn "a regular organization into a liminal one" (2003:279). They can move back and forth across project (or organizational) boundaries, sharing documents between team members, and often pulling the clients into fieldwork, then moving back inside the organization again to present a final project report. The entire process is transitional, uncertain, and open to possibility. Anthropologists are already complex people adept at managing complexity and ambiguity to create new knowledge and innovate using this liminal oscillation as a source of strength. They are in an excellent position to tap into their toolkit and pull out the liminality concept, putting it to good use in global organizations that need their help.

For example, anthropologists could use the concept of liminality as part of delivering corporate training or leadership coaching. Teaching leaders to engage in the practice of taking field notes from time to time, especially when they are faced with a knotty problem, could help them apply more extensive complexity to their own thinking (Denison et al. 1995). Field notes can serve as a mechanism of detachment that could help leaders examine a problem from multiple perspectives and enhance their problem solving ability. Incorporating liminality as part of corporate training also can help build leader capacity to examine problems from multiple perspectives, introducing more creativity and innovation into day-to-day work. This skill has a tendency to get lost as organizational forms have become specialized and leaders have narrowed views of their environment as a result. Thinking liminally is a creative act in and of itself. When applied in the context of solving business problems or making an organization more innovative, liminality can be powerful. A liminal lens could enable a broader line of sight into the different parts of 
the organizational network.

Second, as researchers who wish to expand theory in the era of global networked organizing, liminality offers the opportunity to link this concept and theory from anthropology with others in organization science, information science, or leadership and management theory. One idea might be to couple the concept of liminality with metacognition (Thomas et. al. 2008) as an indicator of complex thinking and the ability to hold multiple perspectives simultaneously. One could experiment with leadership development that is designed to build liminal thinking skills and see if this training actually helps enhance a leaders metacognition.

Another idea for a new research direction involving the application of liminality would be to look at the relationship between new modes of communication (Gluesing and Gibson 2003) and liminality. Does engaging in asynchronous communication create a state of liminality? Research could investigate this and other communication modalities to explore the ways that liminality operates at the macro and micro levels in organizations, in order to learn more about how to apply liminal strategies in different organizational situations, both within and between organizations, and how to develop human resources.

The global work environment presents many complexities that are cultural, structural, technological and interpersonal. Liminality is an anthropological construct that is promising-both for engaging in organizational life and for exploring it as new ways of working emerge.

\section{References}

Appadurai, A. 1996. Modernity at large: Cultural dimensions of globalization. Minneapolis, MN: University of Minnesota Press.

Ashby, W.R. 1973. Introduction to cybernetics. London, UK: Chapman \& Hall.

Bateson, G. 1972. Steps to an ecology of mind: Collected essays in anthropology, psychiatry, evolution, and epistemology. Chicago, IL: University of Chicago Press.

Bourdieu, P. 1996. The rules of art, genesis and structure of the literary field. Cornwall, CA: Stanford University Press.

Bourdieu, P. 1991. The peculiar history of scientific reason. Sociological Forum 6(1): 3-26.

Brannen, M.Y. and D.C. Thomas. 2010. Bicultural individuals in organizations: Implications and opportunity. International Journal of Cross Cultural Management 10(1): 5-16.

Cohen, D.J. and L. Prusak. 2001. In good company: How social capital 
makes organizations work. Boston, MA: Harvard Business School Press. Cook-Sather, A., and Z. Alter. 2011. What is and what can be: How a liminal position can change learning and teaching in higher education. Anthropology \& Education Quarterly 42(1): 37-53.

Czarniawska, B., and C. Mazza. 2003. Consulting as a liminal space. Human Relations 56(3): 267-290.

Denison, D.R., R. Hooijberg, and R.E. Quinn. 1995. Paradox and performance: Toward a theory of behavioral complexity in managerial leadership. Organization Science 6(5): 524-540.

Fitzsimmons, S.R., C. Miska, and G. Stahl. 2011. Multicultural employees: Global business' untapped resource. Organizational Dynamics 40(3): 199206.

Fitzsimmons, S.R. 2013. Multicultural employees: A framework for understanding how they contribute to organizations. Academy of Management Review 38(4): 525-549.

Friedman, T. 2000. The Lexus and the olive tree. New York, NY: Farrar, Strauss and Giroux.

Garston, C. 1999. Betwixt and between: Temporary employees as liminal subjects in flexible organizations. Organization Studies 20(4): 601-617.

Gluesing, J., K. Riopelle, K. Chelst, A. Woodliff, and L. Miller. 2008. An educational partnership for immediate impact. In Partnering for Organizational Performance: Collaboration and Culture in the Global Workplace. E.K. Briody and R.T. Trotter, II, eds. Lanham, MD: Rowman \& Littlefield Publishers, Inc., 125-141.

Gluesing, J.C. and C. Gibson. 2003. Designing and forming effective global teams. In Handbook of global management: A guide to managing complexity. H.W. Lane, M.L. Maznevski, M. Mendenhall and J. McNett, eds. Malden, MA: Blackwell, 199-226.

Hong, Y.-Y., M.W. Morris, C.-Y. Chiu, and V. Benet-Martínez. 2000. Multicultural minds: A dynamic constructivist approach to culture and cognition. American Psychologist 55: 709-20.

Horvath, A. 2009. Introduction: Liminality and cultures of change. International Political Anthropology 2(1): 3-4.

Howard-Grenville, J., K. Golden-Biddle, J. Irwin, and J. Mao. 2011. Liminality as cultural process for cultural change. Organization Science 22(2): 522-539.

IBM. 2010. Capitalizing on complexity: Insights from the global chief executive officer study. IBM Institute for Business Value.

Jackson, J.E. 1990. “DEJA ENTENDU”: The liminal qualities of anthropological fieldnotes. Journal of Contemporary Ethnography 19(1): 8-43. 
Knoke, D. 1999. Organizational networks and corporate social capital. In Corporate social capital and liability. R.Th.A.J. Leenders and S.M. Gabbay, eds. Boston, MA: Kluwer, 17-42.

Lane, H.W., with M.L. Maznevski, and M. Mendenhall. 2004. Globalization: Hercules meets Buddha. In The Blackwell handbook of global management: A guide to managing complexity. H. Lane, M. Maznevski, M. Mendenhall, and J. McNett, eds. Malden, MA: Blackwell, 3-25.

Miller, C., J. Siebert, J. Gluesing, and A. Goldmacher. 2008. The challenge of partnerships in complex cultural environments. In Partnering for Organizational Performance: Collaboration and Culture in the Global Workplace. E.K. Briody and R.T. Trotter, II, eds. Lanham, MD: Rowman \& Littlefield Publishers, Inc., 159-176.

Sachs, J. 2000. International economics: Unlocking the mysteries of globalization. In Globalization and the challenges of a new century: A reader. P. O'Meara, H. D. Mehlinger, and M. Krain, eds. Bloomington and Indianapolis, IN: Indiana University Press, 217-226.

Senge, P.M. 1990. The fifth discipline: The art \& practice of the learning organization. New York: Doubleday.

Stiglitz, J. E. 2002. Globalization and its discontents. New York, NY: W. W. Norton.

Sturdy, A., M. Schwarz, and A. Spicer. 2006. Guess who's coming to dinner? Structures and uses of liminality in strategic management consultancy. Human Relations 59(7): 929-960.

Tempest, S. and K. Starkey. 2004. The effects of liminality on individual and organizational learning. Organization Studies 25(4): 507-527.

Thomas, D.C., E. Elron, G. Stahl, B.A. Ekelund, E.C. Ravlin, J.-L. Cerdin, S. Poelmans, R. Brislin, A. Pekerti, Z. Aycan, M. Maznevski, K. Au, and M.B. Lazarova. 2008. Cultural intelligence: Domain and assessment. International Journal of Cross Cultural Management 8:123-143.

Turner, V. 1974. Dramas, fields, and metaphors: Symbolic action in human society. Ithaca, NY: Cornell University Press.

Turner, V. 1995. Ritual process: Structure and antistructure. New York, NY: Walter de Gruyter.

United Nations Statistics Division. 2011. UNSD Demographic Statistics. http://data.un.org; accessed April 11, 2012.

Weick, K.E. and P.W. Van Orden. 1990. Organizing on a global scale: A research and teaching agenda. Human Resource Management 29(1): 49 61.

Wenger, E. 1998. Communities of practice. New York, NY: Cambridge University Press. 
Julia C. Gluesing, Ph.D. is President of Cultural Connections, Inc., a research, consulting, and education firm supporting global networked organizations. She is also a business and organizational anthropologist and Research Professor in Industrial and Systems Engineering at Wayne State University where she teaches global perspectives in engineering management, global leadership, and qualitative research methods courses in the Global Executive Track Ph.D. From 2005-2010, Dr. Gluesing was the Principal Investigator on a National Science Foundation Grant, the "Digital Diffusion Dashboard," studying the diffusion of innovation across the global enterprise by tapping into an organization's information technology infrastructure. She may be reached at gluesing@teamcci.com. 